\title{
Obstacles To The Adoption Of The IAS/IFRS In Tunisia
}

Salem Lotfi Boumediene, Montana State University Billings, USA

Ridha Zarrouk, University of Manouba, Tunisia

Ines Tanazefti, University of Manouba, Tunisia

\begin{abstract}
To guarantee the production of financial information that is useful for economic decision-making, most countries have a set of accounting standard used in preparing the financial statements. Indeed, the use of a common accounting language by all companies operating in the same economic space allows different users to monitor the activities of these entities in time and space and, therefore, take reasonable decisions. Thereby, the international accounting standards are a necessary to clarify the financial disclosure and make reading financial statements conform to a single repository easier. This strengthens the investor's confidence, stimulates the financial market and ensures the best qualities that the financial information should be endowed. In deciding to adopt the international accounting standards IAS/IFRS, Tunisian authorities have launched a challenge to prompt a fast and adequate transition to a new accounting, financial, informational, organizational and internal control systems. However, this presents some obstacles related to the nature of the Tunisian economy which is characterized by a strong presence of small and medium companies, to the differences between the tax system and the accounting system, the conservative attitude of leaders and the high concentration of ownership.
\end{abstract}

The results of our research analysis shows that the conservative attitude of managers and the lack of dynamic and efficient markets are the most important obstacles to adoption of IAS/IFRS in Tunisia according to the Tunisians Certified Public Accountants TCPAs). We detailed our analysis for the accounting, tax and economic obstacles. For the accounting, we found that the application of IAS 19, IAS 36 and IFRS 4 are the standards that cause more problems at the moment of their implementation according to the TCPAs. In addition, the deferred tax, the actuarial method and the treatment financial instruments are the most complex treatments in IAS/IFRS. Finally, the differences between the Tunisian accounting system and the international system are undoubtedly an important obstacle. Concerning the tax obstacles, we found that companies prepare their financial statements first in accordance with tax rules. In fact, the differences between the tax rules of the Tunisian accounting system and the IAS/IFRS are undoubtedly an obstacle to a better adoption of them. In addition, another obstacle is the readiness of tax administration for the adoption of the IAS/IFRS. Finally, for the economic obstacles, we found that the IAS/IFRS' adoption and implementation costs and the costs related to their enforcement are the main economic obstacles.

Keywords: IAS/IFRS Adoption; Accounting Obstacles; Tax Obstacles; Economic Obstacles

\section{INTRODUCTION}

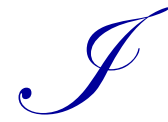
$\mathrm{n}$ order to ensure the production of financial information that is useful for economic decision-making, most countries have a set of accounting standards used in preparing the financial statements. Indeed, the use of a common accounting language by all companies operating in the same economic space allows different users to monitor the activities of these entities in time and space and, therefore, take reasonable decisions.

Thus, the international accounting standards have become essential to clarify the financial disclosure and make reading financial documents conform to a single repository easier. This strengthens the investor's confidence, stimulates the financial market and ensures the best qualities that the financial information should be endowed. 
In deciding to adopt the international accounting standards IAS/IFRS, Tunisian authorities have launched a challenge to prompt a fast and adequate transition to a new accounting, financial, informational, organizational and internal control systems.

Success in this task involves the reproduction of a process of "change management" to measure the complexity and depth of the new accounting standards. This concerns all the stakeholders, the information systems and the procedures.

The Tunisian accounting system and the accounting culture that emerged out of it, lies on a path that promotes the transition to IFRS thanks to its prerequisites. This explains the usefulness of the debate over the advantages of the adoption of the international accounting standards by the national accounting standard settlers. However, we must not neglect the obstacles of a possible transition to international accounting standards in Tunisia.

The relatively large number of countries that have adopted international accounting standards, and the lack of research dealing with the obstacles and the reasons behind Tunisia's delay in the adoption of the IAS/IFRS have led us to identify and analyze the obstacles to the adoption of these standards in the Tunisian context.

Bessieux et al. (2012); Zeghal \& Mhedhbi (2006); Abdelsalam \& Weetman (2003) and Choi \& Meek (2008) have attempted to identify factors that help ensure a better adoption of international accounting standards and the lack of research addressing the barriers to the adoption of IAS/IFRS have led us to identify and analyze the barriers to the adoption of these standards in Tunisia. It is in this context that this research paper is conducted.

Thus, the objective of our research is to identify the various obstacles to the adoption of the international accounting standards IAS/IFRS in Tunisia in order to guarantee a better adoption of these standards without any difficulties, and to establish a typology of obstacles to the adoption of international accounting standards IAS/IFRS in Tunisia according to the profile of the Certified Public Account (CPAs).

In this paper, we first present the literature review, the methodology then the survey results analysis and finally the conclusion.

\section{LITERARY REVIEW}

There are many obstacles that hamper the transition to IAS/IFRS. In this study, we will focus on accounting, fiscal and economic obstacles.

\subsection{Fiscal Obstacles}

The tax component is of great importance in the process of transition to IAS/IFRS in Tunisia. Indeed, because of the close relationship between accounting and taxation, the transition to IAS/IFRS may have a significant impact on taxes in Tunisia. Preparing taxes on the basis of statements prepared in accordance with IAS/IFRS poses several questions such as the tax consequences that may create IFRS 1, IAS 32, IAS 39, IAS 11 standards among others.

IAS/IFRS are disconnected from taxation, that's why many practitioners call for a complete review of the tax framework calling for a full separation from the financial statement. We will try to study the influence that taxation may have on the process of transition to IAS/IFRS.

\subsubsection{The Influence of Tax Rules on the Adoption and Implementation of IFRS}

According to Street \& Larson (2004), the obstacles that may hinder the adoption of IAS/IFRS are influenced by tax rules. This is explained by the fact that the full implementation of the international accounting standards normally results in greater discrepancy between accounting income and tax income. Thus, the tax base is rarely the same as the accounting net income because there is always more and less reconciliation between accounting net income and tax base. 
Studies conducted by Jermakowicz (2004); Sucher \& Jindrichovska (2004); Vellam (2004) have focused on the transition and implementation of IAS/IFRS. These studies have shown that the problems of implementation of IAS/IFRS in the European Union (EU) are largely related to the preparation of accounting information for tax purposes that do not meet the investors' needs and the users' orientations of the financial information produced according to IAS/IFRS.

Street \& Larson (2004) conducted a study on EU companies to test the factors and the obstacles to the transition to IAS/IFRS before their mandatory adoption by listed companies in 2005. The results showed that most of the companies listed in the EU did not intend to adopt international accounting standards. The main obstacles are based on the increasing difficulties in the application of certain IAS/IFRS, the country tax system and the absence of guidance for the implementation of such standards.

Disle \& Noël (2007) showed that France has always given priority to tax over financial reporting. According to the IAS/IFRS, companies must show its real economic value and produce an accurate and attractive image to attract investors and stakeholders. The French context is characterized by the application of strict rules that according to Gélard (2006) are prepared and revised to meet the requests of a particular sector based on tax considerations.

In addition, Gélard (2006) explained that the International Accounting Standard Board (IASB) is very reluctant to the idea of differentiation by sector, which disrupts the habits of French professionals. Therefore, French accounting followed a tax approach to communicate with the tax administration by highlighting the reliability of the figures produced. Stakeholders and investors had to settle for these accounting documents intended primarily to the tax administration (Evraert \& Robert (2007).

\subsubsection{Accounting - Tax Divergences}

Accounting and taxation are two independent disciplines that serve different purposes. Financial accounting is used to measure companies' earnings through economic flows. It aims at describing the company's financial position, its assets statement and its performance. Financial accounting also aims at meeting the needs of investors at risk, shareholders and investors. It aims also at determining the principles and rules of assessment of taxable earnings. In case of divergences, the accounting and tax earnings are conceivable (Shaviro (2009)).

Accounting and tax divergences has been the subject of an academic debate, it has emerged and evolved for a long time (Manzon \& Plesko (2002) and Desai \& Dharmapala (2006)). In Tunisia, accounting and taxation are two separate disciplines, they have a common field. Indeed, the determination of taxable income is based on accounting income. In fact, in Tunisia, accounting regulation is independent of tax regulations, thus creating differences in objectives, and particularly differences in the income (accounting income and taxable income). The specificities of the Tunisian context is characterized by an accounting system that provides some flexibility in the choice of accounting policies, and by a flexible tax legislation characterized by a tax benefits system offering a wide latitude in terms of tax management that creates a favourable ground for discretionary earnings and tax management practices, which creates discrepancies in earnings.

According to Yaïch (2006), the approach of IAS/IFRS completely contrasts with the tax rules since the determination of the income taxes is done outside the accounting system. Three types of discrepancies exist, demonstrating the complexity of the problem. First, there are differences between the Tunisian accounting and tax systems. Second, there are differences between the local GAAP and IAS/IFRS. Finally, this situation creates differences between IAS/IFRS and Tunisian tax system.

\subsection{Accounting Obstacles}

Some treatments recommended by the IAS/IFRS are hardly acceptable due to the inconsistency of the practices with IAS/IFRS principles and the complexity of certain accounting rules and treatment. 


\subsubsection{The Incompatibility of Practices in Effect with IFRS Principles}

Certain treatments recommended by the IAS/IFRS are difficult to accept because they do not agree with current accounting practices and culture. According Hail et al. (2010), a transition to IAS/IFRS by the United States could have undesirable results for the American economy if it is incompatible with other elements of the institutional framework, even when IAS/IFRS are deemed to be of high quality and had good results in other countries.

\subsubsection{The Complexity of Some Rules and Accounting Treatments}

The complexity of certain rules especially those related to the fair value represents an obstacle to a better adoption of IAS/IFRS. Haller (2002) considers that there is no way for the harmonization of accounting rules. Jermakowicz et al. (2007) showed that the majority of German companies that used IAS/IFRS did it only for the preparation of their consolidated financial statements.

Mir \& Rahaman (2005) found that the increased use of the sophisticated rules of IAS/IFRS is not suitable for the less complex economic and regulatory structures of Bangladesh. Bhattacharjee \& Islam (2009) added through their research that most accountants consulted expressed doubt about the suitability of the adoption of IAS/IFRS in Bangladesh. In addition, some treatments recommended by the IAS/IFRS are difficult to understand, to master and to apply, such as, the treatment of financial instruments, the application of the actuarial method, the assets depreciation and the revaluation of assets.

\subsection{Economic Obstacles}

The current logistics cannot be used to support the introduction of IAS/IFRS. Apart from the changes and implications of accounting nature, the transition to IAS/IFRS requires technical, human and financial resources at the level the standardization body as well as at the level of the company. The process related to the transition of local standards to IAS/IFRS is considered expensive and complex due to the complexity and the absence of a guide that could direct businesses. The costs of transition to IAS/IFRS can be classified into two categories, costs of adoption and implementation and costs related to the use of IAS/IFRS (Jopson (2005).

\section{METHODOLOGY}

In this section, we intend to confirm the obstacles to the adoption of IAS/IFRS through an empirical validation conducted in the Tunisian context. As part of our research, a questionnaire is the most appropriate method for the data collection.

\subsection{Operational Framework}

The relatively considerable number of research that has attempted to identify factors that ensure a better adoption of international accounting standards, and the lack of research addressing the obstacles to adoption of IAS/IFRS have prompted us to identify and analyze these obstacles in the Tunisian context. In Tunisia, the phenomenon of globalization, the growing number of multinational companies and the opening of financial markets to foreign investors, create the need of the adoption of the IAS/IFRS. However, some IAS/IFRS treatments are difficult to accept because they do not correspond to the current accounting practices and culture.

The widespread application of fair value is difficult because the Tunisian financial market is relatively new. It has some limitations that are manifested through a slow development and a reduced number of listed companies. The Tunisian financial market is also characterized by a low liquidity and insufficient financial information. This situation raises the question of the compatibility of IAS/IFRS with the Tunisian context.

Tunisia has tried to get closer to IAS/IFRS by transitioning from a chart of accounts model (1968) to a conceptual accounting system (1996). However, 18 years after its issuance, the Tunisian Accounting Standards (TAS) has not been significantly updated to reflect multiple and substantial changes introduced by the IAS/IFRS. In addition, the TAS remained incomplete on major issues. 


\subsection{The Development of the Questionnaire}

The absence of previous empirical research on the issue of the obstacles to the adoption of IAS/IFRS in Tunisia has given our research its exploratory nature. Exploratory research usually favours a qualitative research approach because of the lack of previous research. The objective of this empirical study is to see how the Tunisian accountants perceive the adoption of international accounting standards IAS/IFRS in Tunisian companies with regards to usefulness obstacles of accounting nature. To carry out our research and to develop a questionnaire that could give relevant results, we have performed a literature review that helped us in the formalization of the questionnaire and in the determinations of different questions; and an in-depth exploratory research based on a direct interview with experts in our research field.

\subsection{Qualitative Test of the Questionnaire or the Pre-test}

It is commonly accepted that the distribution of the questionnaire cannot start without a preliminary test which aims at detecting the potential anomalies related to the content and visual appearance of the statements of which they are composed (Churchill (1995), Bearden \& Netemeyer (1999)). In this context, Churchill (1995) argues that the qualitative preliminary test (pre-test) is an examination of the questions on a small sample in order to identify and correct problems of assimilation and avoid confusion of any kind. The pre-test aims at assessing the reliability of the questions as well as at measuring their efficiency. Indeed, it is about checking how easy it is to understand the questions and the extent to which the respondents accept them. In this regard, we asked three CPAs (from the sample) to give us their feedback on the understanding and the readability of each question. This approach had enabled us to improve the wording of some questions and to add others.

In addition, CPAs surveyed during the pre-test reported a few items that are difficult to assimilate. Thus, we opted for the inclusion of additional information (for more explanation and precision) merging some questions and eliminating some unnecessary questions. From this qualitative test, several suggestions were retained to improve the intelligibility of the statements; moreover, this approach has allowed us to improve the list of the questions and to compile an updated list to be used in the creation of the questionnaire (the questionnaire is available upon request).

\subsection{The Sample}

Given the nature of our research, the chosen population necessarily consists of CPAs. Our decision was to choose the Tunisian CPAs (TCPAs) for their knowledge of standards. To realize this research, we excluded from the study, the trainee CPAs, since they do not have as much experience as the full CPAs. The questionnaire was sent to 400 Tunisian TCPAs, the total population of the TCPSs (including the Certified Public Account) is 854 (46.84\%). We were able to collect the responses from 71 TCPAs, thus the response rate of $17.75 \%$.

\subsection{Sample Characteristic}

Table 1 details the characteristics of the responses. The teaching TCPAs represents 45.07 of the respondent while the non-teaching TCPAs represent $54.93 \%$.

Table 1. Characteristics of respondents according to their current position

\begin{tabular}{l|c|c}
\hline & Number & Frequency \\
\hline Teaching TCPAs & 32 & $45.07 \%$ \\
\hline Non-teaching TCPAs & 39 & $54.93 \%$ \\
\hline Total & 71 & $100.00 \%$ \\
\hline
\end{tabular}

The analysis of the composition of the sample presented in Table 2 shows that $32.39 \%$ of respondents have a professional experience of less than 10 years; $28.17 \%$ of the respondents have between 10 and 20 years professional experience; $22.54 \%$ of the respondents have between 20 and 30 years professional experience and $16.90 \%$ of the respondents have a professional experience of over 30 years. 
Table 2. Characteristics of respondents by the number of years of professional experience

\begin{tabular}{l|cc}
\hline \multicolumn{1}{c}{ Professional experience } & Number & Frequency \\
\hline Less than 10 years & 23 & $32.39 \%$ \\
\hline Between 10 and 20 & 20 & $28.17 \%$ \\
\hline Between 20 and 30 & 16 & $22.54 \%$ \\
\hline More than 30 years & 12 & $16.90 \%$ \\
\hline Total & 71 & $100.00 \%$ \\
\hline
\end{tabular}

From Table 3, one can see that $78.87 \%$ of the TCPAs have a national customer network, however, the international customer network is under-represented within the sample. This can be explained by the fact that the Tunisian economy is marked by the important number of Small and Medium Enterprises (SMEs).

Table 3. Characteristics of respondents by type of customer network

\begin{tabular}{l|cc}
\hline \multicolumn{1}{c|}{ Customer network type } & Number & Frequency \\
\hline International & 7 & $9.86 \%$ \\
\hline National and international & 8 & $11.27 \%$ \\
\hline National network & 56 & $78.87 \%$ \\
\hline Total & 71 & $100.00 \%$ \\
\hline
\end{tabular}

\subsection{Data Collection Method}

Our study is exploratory; it aims at collecting views of respondents. For this reason, the questionnaire is the most appropriate data collection method. First, we contacted chartered accountants, to ask them if they agree to participate in the questionnaire. For those who agreed, we gave them a questionnaire that has to be filed. The questionnaire was either sent by e-mail or directly handed. The majority of questionnaires were administered electronically. We did not use the phone to administer the questionnaire for the reason that it may influence the respondent and cause significant statistical bias.

\section{SURVEY RESULTS ANALYSIS}

To analyze the results of the survey, we used SPSS (version 21) to conduct a Descriptive Analysis (DA), a Principal Component Analysis (PCA) and a Hierarchical Cluster Analysis (HCA) of the different obstacles.

\subsection{Descriptive Analysis (DA)}

The theoretical part of our research has allowed us to identify a set of obstacles that can be introduced during the adoption of IAS/IFRS.

\subsubsection{Obstacles to Adoption of IAS/IFRS in Tunisia According to Their Degree of Importance}

The questions raised in this section deal with the different types of obstacles to the adoption of international accounting standards IAS/IFRS in Tunisia. The results we have reached allow us to conclude that all these obstacles are significant and it is noted that the conservative attitude of managers and the lack of dynamic and efficient markets are the most observed. Then comes the pro-cyclical nature of fair value. Tax regulations and tax liability is in fourth position. The complexity of some rules and accounting treatment is in fifth position. The cost of adoption and implementation of IAS/IRFS in Tunisia is in sixth position. The incompatibility of practices with the principles of IAS/IFRS remains in last position. Table 4 details these results. 
Table 4. Obstacles to adoption of IAS/IFRS in Tunisia according to their degree of importance

\begin{tabular}{|c|c|c|c|c|c|}
\hline Obstacles & 1 & 2 & 3 & 4 & 5 \\
\hline Tax regulations and tax liability & $7 \%$ & $4 \%$ & $9 \%$ & $47 \%$ & $33 \%$ \\
\hline Incompatibility of practices with the principles of IAS/IFRS & $4 \%$ & $25 \%$ & $12 \%$ & $36 \%$ & $23 \%$ \\
\hline Complexity of some rules and accounting treatment & $8 \%$ & $19 \%$ & $10 \%$ & $31 \%$ & $32 \%$ \\
\hline Pro-cyclical nature of fair value & $2 \%$ & $13 \%$ & $7 \%$ & $40 \%$ & $38 \%$ \\
\hline Cost of adoption and implementation of IAS/IRFS in Tunisia & $3 \%$ & $9 \%$ & $10 \%$ & $49 \%$ & $29 \%$ \\
\hline Lack of dynamic and efficient markets & $2 \%$ & $7 \%$ & $10 \%$ & $33 \%$ & $48 \%$ \\
\hline Conservative attitude of managers & $0 \%$ & $7 \%$ & $12 \%$ & $33 \%$ & $48 \%$ \\
\hline
\end{tabular}

1: Not important; 3: Neutral; 5: Very Important

\subsubsection{Accounting Obstacles}

The questions raised in this section deal with the obstacles of accounting nature that hamper the transition to IAS/IFRS namely, the incompatibility of practices with the principles of IAS/IFRS and the complexity of these standards.

\subsubsection{The Problems of Accounting Nature that May Arise During the Application of IAS/IFRS in Tunisia}

Over $70 \%$ of TCPAs consider the application of the IAS 19, the IAS 36 and the IFRS 4 are the standards that cause more problems at the moment of their implementation. Some TCPAs raised other problems and obstacles of accounting nature such as; the application of the IAS 12 and 39, and the IFRS 1 and 9; the lack of market indicators that facilitates the work of assessment and estimation; In general, the problems lie at all levels where there is a new situation compared to the current; and there is always an aversion to change. Table 5 details these findings.

Table 5. Problems of accounting nature that may arise during the application of IAS/IFRS in Tunisia

\begin{tabular}{l|c|c|c|c|c}
\hline \multicolumn{1}{c|}{ Obstacles } & $\mathbf{1}$ & $\mathbf{2}$ & $\mathbf{3}$ & $\mathbf{4}$ & $\mathbf{5}$ \\
\hline Fair value determination & $1 \%$ & $9 \%$ & $6 \%$ & $32 \%$ & $52 \%$ \\
\hline Application of IAS 36 & $1 \%$ & $7 \%$ & $13 \%$ & $49 \%$ & $29 \%$ \\
\hline Application of IAS 19 and IFRS4 & $3 \%$ & $7 \%$ & $16 \%$ & $42 \%$ & $31 \%$ \\
\hline
\end{tabular}

1: Not important; 3: Neutral; 5: Very Important

\subsubsection{The most complex rules and accounting treatment according to IAS/IFRS}

$67 \%$ of TCPAs consider that the deferred tax, the actuarial method and the treatment financial instruments are the most complex treatments in IAS/IFRS. So, according to the responses of TCPAs, the treatments of financial instruments are the most complex processing compared to other treatments and rules. Some TCPAs added other rules and complex accounting treatments such as Insurance Contracts; the decommissioning cost; the business combination under common control; and identification of cash-generating units.

Table 6. The problems of accounting nature that may arise during the application of IAS/IFRS in Tunisia

\begin{tabular}{|c|c|c|c|c|c|}
\hline Obstacles & 1 & 2 & 3 & 4 & 5 \\
\hline Deferred tax & $7 \%$ & $16 \%$ & $9 \%$ & $57 \%$ & $10 \%$ \\
\hline Actuarial methods & $3 \%$ & $10 \%$ & $10 \%$ & $54 \%$ & $23 \%$ \\
\hline Treatments of financial instruments & $0 \%$ & $4 \%$ & $9 \%$ & $47 \%$ & $40 \%$ \\
\hline Treatments of secondary instruments: drifts and hedging instruments & $2 \%$ & $6 \%$ & $9 \%$ & $39 \%$ & $44 \%$ \\
\hline
\end{tabular}

1: Not important; 3: Neutral; 5: Very Important

4.1.2.3. The Incompatibility or the Differences Between the Tunisian and the International Repository

According to Table 7, 49\% of TCPAs agree that the comparison between the Tunisian and the international repository revealed very significant differences; $30 \%$ believe that there are little differences but they are important. 
Table 7. Comparison between Tunisian and international repository

\begin{tabular}{l|c}
\hline The comparison shows very important differences. & $49 \%$ \\
\hline There is multitude of differences but they are insignificant & $17 \%$ \\
\hline There is few of differences but they are important & $30 \%$ \\
\hline The two repository are almost alike except a few unimportant differences & $4 \%$ \\
\hline
\end{tabular}

$70 \%$ of TCPAs $70 \%$ consider that the differences between the Tunisian accounting system and the international system are undoubtedly an obstacle to a better understanding of financial information at the international level. This finding confirms the importance of differences, which are numerous.

The comparison between the Tunisian and the international repository revealed very important differences that are undoubtedly an obstacle to a better understanding of financial information at the international level and a hinder to the transition to IAS/IFRS since it is more difficult to adjust differences between the Tunisian and the international repository than to simply adopt the Tunisian accounting standards with the international ones.

\subsubsection{Fiscal Obstacles}

The questions raised in this section deal with tax obstacles that hamper the transition to IAS/IFRS namely the tax systems, the tax liability and the differences between accounting and taxation.

\subsubsection{The Extent of the Influence of the Tunisian Tax Accounting Rules}

$80 \%$ of Tunisian TCPAs believe that companies prepare their financial statements first in accordance with tax rules and then in accordance with accounting regulations. In addition, the majority of TCPAs (65\%) opt for the tax rule in preparing the financial statements, in situations where the tax rule is in contradiction with the accounting rule. In conclusion, companies prepare their financial statements first in accordance with tax rules. In fact, $62 \%$ of TCPAs confirm that the Tunisian tax rules may hinder the transition to IAS/IFRS.

4.1.3.2. The differences between the tax rules of the Tunisian accounting system and the international system are undoubtedly an obstacle to better adoption of international accounting standards. In fact, $59 \%$ of TCPAs confirm that the differences between the tax rules of the Tunisian accounting system and the IAS/IFRS are undoubtedly an obstacle to a better adoption of them. This is explained by:

- The Tunisian laws and regulations prohibit the assets re-evaluation while the IAS/IFRS allow it based on the concept of fair value;

- The tax rules are rigid and adhere to the principle of prudence while the rules and treatment according to the IAS/IFRS are based on the economic reality over the legal form;

- The current accounting system is governed by arbitrary and customized tax measures;

- The complexity of the tax rules in Tunisia as well as an inconsistent accounting system that had not been updated since 1996;

- Companies prepare their financial statements mainly in accordance with tax rules.

On the other hand, $41 \%$ of TCPAs believe that the difference between the Tunisian accounting system tax rules and the IAS/IFRS does not clearly hinder a better adoption of international accounting standards. This can be explained by:

- TCPAs are already aware of these differences and are taking them into consideration when preparing financial statements;

- The Tunisian tax system may be attractive to foreign investors;

- Due to the absence of a tax department, the accounting department usually prepares financial statements and tax returns.

- The tax and accounting difference issues are always treated in an extra accounting system;

- The accounting system should be treated independently from fiscal and governmental requirements regulations. 


\subsubsection{Preparedness of the Tax Administration}

After showing that the tax regulations and the differences between accounting and taxation are the main tax obstacles to the adoption of the IAS/IFRS in Tunisia, we tried to see if the Tax administration is getting prepared for their adoption. According to Table $8,35 \%$ of the TCPAs consider that the Tax administration is getting ready but it will take time, while $9 \%$ of them consider that the Tax administration is not getting ready.

Table 8. Preparedness of the Tax administration

\begin{tabular}{l|c}
\hline Yes, and it will be activated & $3 \%$ \\
\hline Yes, getting ready but it will take time & $35 \%$ \\
\hline May be, getting ready but it will take time & $33 \%$ \\
\hline There is no relation & $20 \%$ \\
\hline No & $9 \%$ \\
\hline
\end{tabular}

\subsubsection{Economic Obstacles}

The questions raised in this section deal with economic obstacles that hamper the transition to IAS/IFRS namely the adoption and implementation costs of IAS/IFRS and the costs related to their enforcement.

\subsubsection{Transition Cost by Type of Company}

According to Table 9, companies with foreign subsidiaries are companies that will have to pay more money as a transition cost. Subsequently, there are companies operating only in Tunisia and companies with a customer base and finally the companies audited by the BIG 4 . So the adoption of IAS/IFRS will be more costly for companies with subsidiaries outside Tunisia.

Table 9. Transition cost by type of company

\begin{tabular}{l|l}
\hline Companies operating only in Tunisia & $21 \%$ \\
\hline Companies having subsidiaries outside Tunisia & $28 \%$ \\
\hline SME & $28 \%$ \\
\hline Companies having international customers & $14 \%$ \\
\hline
\end{tabular}

\subsubsection{Transition Costs}

For the transition costs to IAS/IFRS, we found that $90 \%$ of TCPAs consider that the costs of adoption and implementation of IAS/IFRS are important. In addition, $86 \%$ of TCPAs consider the costs associated with the implementation of IAS/IFRS standards are important. To summarize, the transition to IAS/IFRS is more costly at their application than at their adoption and implementation. Table 10 details these findings.

Table 10. Transition costs

\begin{tabular}{l|c|c|c|c|c}
\hline \multicolumn{1}{c|}{ Obstacles } & $\mathbf{1}$ & $\mathbf{2}$ & $\mathbf{3}$ & $\mathbf{4}$ & $\mathbf{5}$ \\
\hline Costs related to adopting the IAS/IFRS & $4 \%$ & $3 \%$ & $3 \%$ & $46 \%$ & $44 \%$ \\
\hline Costs related to applying the IAS/IFRS & $3 \%$ & $8 \%$ & $3 \%$ & $44 \%$ & $42 \%$ \\
\hline Total & $7 \%$ & $11 \%$ & $6 \%$ & $90 \%$ & $86 \%$ \\
\hline
\end{tabular}

1: Not important; 3: Neutral; 5: Very Important

\subsubsection{Adoption and Implementation Costs}

We break down the costs of adoption and implementation into educational and training costs and costs related to the reorganization and change in the information system. From the answers of the TCPAs, we note that the costs of training and education are the most important. Then come the expenses related to the reorganization and modification of the information system. Table 11 details these findings. In addition, TCPAs have recommended other adoption and implementation costs such as the cost of audit and assistance as well as the consulting and coaching cost. 
Table 11. Adoption and implementation costs

\begin{tabular}{l|c|c|c|c|c}
\hline \multicolumn{1}{c|}{ Obstacles } & $\mathbf{1}$ & $\mathbf{2}$ & $\mathbf{3}$ & $\mathbf{4}$ & $\mathbf{5}$ \\
\hline Educational and training costs & $1 \%$ & $3 \%$ & $3 \%$ & $51 \%$ & $42 \%$ \\
\hline Reorganizational and information system update & $1 \%$ & $6 \%$ & $7 \%$ & $38 \%$ & $48 \%$ \\
\hline Total & $2 \%$ & $9 \%$ & $10 \%$ & $89 \%$ & $90 \%$ \\
\hline
\end{tabular}

1: Not important; 3: Neutral; 5: Very Important

Table 12 reports the answer to the question "if the IAS/IFRS would become one day the universal language of accounting". The results show that $49 \%$ of TCPAs think so and assure that the IAS/IFRS standards will eventually become the universal language of accounting, while $4 \%$ do not think so.

Table 12. Can the IAS/IFRS become one day the universal language of accounting

\begin{tabular}{c|c|c|c}
\hline Sure & Probably & Unlikely & I do not believe \\
\hline $49 \%$ & $41 \%$ & $6 \%$ & $4 \%$ \\
\hline
\end{tabular}

\subsection{Principal Component Analysis (PCA)}

In this section, we will, first determine the number of axes, then, judge their reliability. This is measured by the "Cronbach's alpha", which is according to Carricano et al. (2010), "A reliability coefficient which measures the internal consistency of a scale constructed from a set of items. The more the value of alpha is closer to 1, the stronger the internal consistency of the scale (reliability). Therefore, the items that reduce the score are removed and those which increase alpha are kept".

\subsubsection{Obstacles to the Adoption of IAS/IFRS}

From table 13, we can conclude that, in regard to the obstacles to the adoption of IAS/IFRS, two axes can be retained representing $61.318 \%$ of the information. The variable "Major Obstacles" is multidimensional. The first axis represents $46.673 \%$ of the total inertia and is positively correlated with six variables, namely, "tax regulations and tax liability"; "incompatible practices with the principles of IAS/IFRS"; "Complexity of some rules and accounting treatment"; "pro-cyclical nature of fair value"; "cost of adoption and implementation of IAS/IRFS in Tunisia" and "lack of dynamic and efficient markets". The second axis represents $14.645 \%$ of the total inertia. It is composed of the variable "conservative attitude of managers and leaders".

Table 13. Total Variance Explained for the Obstacles to the adoption of IAS/IFRS

\begin{tabular}{c|c|c|c|c|c|c}
\hline \multirow{2}{*}{ Component } & \multicolumn{3}{|c|}{ Initial Eigen values } & \multicolumn{2}{c}{ Extraction Sums of Squared Loadings } \\
\cline { 2 - 7 } & Total & \% of variance & Cumulative \% & Total & \% of variance & Cumulative \% \\
\hline 1 & 3.267 & 46.673 & 46.673 & 3.267 & 46.673 & 46.673 \\
\hline 2 & 1.025 & 14.645 & 61.318 & 1.025 & 14.645 & 61.318 \\
\hline 3 & .786 & 11.235 & 72.553 & & & \\
\hline 4 & .688 & 9.823 & 82.376 & & & \\
\hline 5 & .515 & 7.357 & 89.733 & & & \\
\hline 6 & .396 & 5.654 & 95.387 & & & \\
\hline 7 & .323 & 4.613 & 100.000 & & & \\
\hline
\end{tabular}

Extraction Method: Principal Component Analysis

Bartlett's test tends to zero and is significant; KMO index is significant as well and has a value of 0.789 . Therefore these results are very significant, and the factorization is possible. Cronbach's alpha is 0.805 , thus the scale constructed from all variables represented by this axis is highly reliable.

\subsubsection{Accounting Obstacles}

From the answers to the questions on the most complex accounting standards, one axis can be retained and has $52.009 \%$ of the information; the variable "The Standards and the Treatment the Most Complex" is thus onedimensional. Table 14 details these findings. Bartlett's test tends to zero and is significant; KMO index is significant as well and has a value of 0.764 . Therefore these results are very significant, and the factorization is possible. 
Cronbach's alpha is 0.840 , thus the scale constructed from all variables represented by this axis is highly reliable.

Table 14. Total Variance Explained for the Accounting Obstacles

\begin{tabular}{c|cc|c|c|c|c}
\hline \multirow{2}{*}{ Component } & \multicolumn{3}{|c|}{ Initial Eigen values } & \multicolumn{2}{c}{ Extraction Sums of Squared Loadings } \\
\cline { 2 - 7 } & Total & \% of variance & Cumulative \% & Total & \% of variance & Cumulative \% \\
\hline 1 & 3.641 & 52.009 & 52.009 & 3.641 & 52.009 & 52.009 \\
\hline 2 & .916 & 13.082 & 65.091 & & & \\
\hline 3 & .852 & 12.172 & 77.263 & & & \\
\hline 4 & .693 & 9.898 & 87.161 & & \\
\hline 5 & .372 & 5.313 & 92.474 & & & \\
\hline 6 & .313 & 4.475 & 96.949 & & & \\
\hline 7 & .214 & 3.051 & 100.000 & & & \\
\hline
\end{tabular}

Extraction Method: Principal Component Analysis

From this factor, we note that "determination of fair value", "application of the actuarial method" "deferred tax", "impairment of assets", "treatment of secondary instruments: drifts and hedging instruments", "employee Benefits" and "treatment of financial instruments" are the most complex treatments and represent obstacles of accounting nature.

\subsubsection{Tax Obstacles}

Concerning the responses to the tax obstacles questions, only 1 axis can be retained representing $87.528 \%$ of the information; the variable "Tax" is thus one-dimensional. Table 15 details these findings. Bartlett's test tends to zero and is significant; KMO index is significant as well and has a value of 0.761 . Therefore, these results are very significant, and the factorization is possible. Cronbach's alpha is 0.929 , thus the scale constructed from all variables represented by this axis is highly reliable.

From this factor, we found that "tax regulations", "absence of a tax reform" and "difference between the Tunisian accounting tax rules and IAS/IFRS" are undoubtedly tax obstacles to their adoption in Tunisia.

Table 15. Total Variance Explained for the Tax Obstacles

\begin{tabular}{c|c|c|c|c|c|c}
\hline \multirow{2}{*}{ Component } & \multicolumn{3}{|c|}{ Initial Eigen values } & \multicolumn{2}{c}{ Extraction Sums of Squared Loadings } \\
\cline { 2 - 7 } & Total & \% of variance & Cumulative \% & Total & \% of variance & Cumulative \% \\
\hline 1 & 2.626 & 87.528 & 87.528 & 2.626 & 87.528 & 87.528 \\
\hline 2 & .214 & 7.127 & 94.655 & & & \\
\hline 3 & .160 & 5.345 & 100.000 & & & \\
\hline
\end{tabular}

Extraction Method: Principal Component Analysis

\subsubsection{Economic Obstacles}

For the economic obstacles, only 1 axis could be selected, representing $64.649 \%$ of the information, the "Cost" variable is thus one-dimensional. Table 16 details these findings. This axis is correlated with "the adoption and implementation costs", "costs related to the application of IFRS" and "training and education expenses related to the reorganization and the modification of the information system". Bartlett's test tends to zero and is significant; KMO index is significant as well and has a value of 0.763 . Therefore, these results are very significant, and the factorization is possible. Cronbach's alpha is 0.807 , thus the scale constructed from all variables represented by this axis is highly reliable.

We can conclude that "cost of adoption and implementation", "costs related to the application of IAS/IFRS" and "training and education expenses related to the reorganization and the modification of the information system" are economic obstacles. 
Table 16. Total Variance Explained the Economic Obstacles

\begin{tabular}{c|c|c|c|c|c|c}
\hline \multirow{2}{*}{ Component } & \multicolumn{3}{|c|}{ Initial Eigen values } & \multicolumn{2}{c}{ Extraction Sums of Squared Loadings } \\
\cline { 2 - 7 } & Total & \% of variance & Cumulative \% & Total & \% of variance & Cumulative \% \\
\hline 1 & 2.586 & 64.649 & 64.649 & 2.586 & 64.649 & 64.649 \\
\hline 2 & .627 & 15.680 & 80.328 & & & \\
\hline 3 & .497 & 12.421 & 92.749 & & & \\
\hline 4 & .290 & 7.251 & 100.000 & & & \\
\hline
\end{tabular}

Extraction Method: Principal Component Analysis

\subsection{Hierarchical Cluster Analysis (HCA)}

\subsubsection{HCA of Obstacles According to the TCPAs Profile}

Table 17 details the results of this classification (the number represent the average for the variable). To summarize, we establish first a typology of the main obstacles according to the TCPAs profile, namely, Customer type and the Number of years of experience of the TCPA. The results found are:

- The pro-cyclical nature of fair value, the cost of adoption and implementation of IAS/IRFS in Tunisia and the incompatible practices with the principles of IAS/IFRS are rated as the most important obstacles by TCPAs having national and international customer networks.

- The lack of dynamic and efficient markets, the tax regulations and liability, the complexity of certain accounting principles and treatments are rated by TCPAs having 10 to 20 years of experience as the most important obstacles.

- The conservative attitude of managers and leaders is seen as the most important obstacle by nonteaching TCPAs.

For the classification of costs according to the TCPAs profile, we note that the costs of training and education and the expenses related to the reorganization and the modification of the information system are rated by TCPAs having networks of international customers as the most important costs.

However, the costs associated with the implementation of IAS/IFRS and the costs of adoption and implementation are considered by TCPAs having 10 to 20 years of experience as the most important obstacles.

Finally, regarding the standards and the most complex treatments, we note that:

- According to the TCPAs having networks of international customers, deferred tax is the most complex treatment.

- The treatment of financial instruments, the treatment of secondary instruments and the application of impairment of Assets are seen by TCPAs with national and international clients networks as the most complex treatment.

- The determination of fair value, the actuarial method and the insurance contracts are the most complicated treatment according to the TCPAs having 10 to 20 years of experience.

\subsubsection{HCA of Obstacles According to the Nature of the Obstacles and the TCPAs Profile}

From Table 18, we establish a typology of obstacles according to the nature the obstacles and the TCPAs profile (the number represent the average for the variable). For accounting obstacles, we notice that:

- According to TCPAs having a network of international customers, deferred tax is the most important obstacle.

- The pro-cyclical nature of the fair value, the incompatibility of practices with the principles of IAS/IFRS, the treatment of financial instruments, the treatment of secondary instruments and the application of impairment of assets are rated by TCPAs having a network of national and international clients as the most important obstacles. 
- The complexity of some rules and accounting treatments, the pro-cyclical nature of fair value, the actuarial method the insurance contracts, and the determination of fair value are the most important obstacles according to TCPAs having 10 to 20 years of experience.

Table 17. HCA of obstacles according to the TCPAs profile

\begin{tabular}{|c|c|c|c|c|}
\hline & & Main Obstacles & Costs & $\begin{array}{l}\text { The most complicated } \\
\text { norms and treatments }\end{array}$ \\
\hline \multirow[t]{3}{*}{ Customer type } & International & & $\begin{array}{l}\text { - Training and education } \\
\text { expenses (4.86) } \\
\text { - Expenses related to the } \\
\text { reorganization and the } \\
\text { modification of } \\
\text { information system (4.71) }\end{array}$ & Deferred Tax (4.0) \\
\hline & National & & & \\
\hline & $\begin{array}{l}\text { National and } \\
\text { international }\end{array}$ & $\begin{array}{l}\text { - The pro-cyclical nature of } \\
\text { the fair value }(4.25) \\
\text { - The adoption and } \\
\text { implementation costs of } \\
\text { IAS/IFRS in Tunisia } \\
(4,13) \\
\text { - The incompatibility of } \\
\text { practices with IAS/IFRS } \\
\text { principles (3.88) }\end{array}$ & & $\begin{array}{l}\text { - Treatment of financial } \\
\text { instruments }(4.50) \\
\text { - Treatment of secondary } \\
\text { instruments: drifts and } \\
\text { hedging instruments } \\
\text { (4.25) } \\
\text { - The application of IAS } \\
36 \text { «assets impairment» } \\
(4.15)\end{array}$ \\
\hline \multirow[t]{4}{*}{$\begin{array}{l}\text { Number of years } \\
\text { of experience }\end{array}$} & $\begin{array}{l}\text { Less than } 10 \\
\text { years }\end{array}$ & & & \\
\hline & $\begin{array}{l}\text { Between } 10 \\
\text { and } 20 \text { years }\end{array}$ & $\begin{array}{l}\text { - The absence of efficient } \\
\text { and dynamic markets } \\
(4.40) \\
\text { - Tax regulations and tax } \\
\text { liability }(4.35) \\
\text { - The complexity of certain } \\
\text { accounting rules and } \\
\text { treatments }(4.05)\end{array}$ & $\begin{array}{l}\text { - Costs related to the } \\
\text { application of IFRS } \\
\text { standards (4.63) } \\
\text { - Adoption and } \\
\text { implementation costs } \\
\text { (4.13) }\end{array}$ & \\
\hline & $\begin{array}{l}\text { Between } 20 \\
\text { and } 30 \text { years }\end{array}$ & & & \\
\hline & $\begin{array}{l}\text { More than } \\
30 \text { years }\end{array}$ & & & \\
\hline \multirow[t]{2}{*}{ Current Position } & $\begin{array}{l}\text { Teaching } \\
\text { TCPA }\end{array}$ & & & \\
\hline & Non- TCPA & $\begin{array}{l}\text { The conservative attitude } \\
\text { of managers and leaders } \\
\text { (4.31) }\end{array}$ & & \\
\hline
\end{tabular}

For tax obstacles, we note that the differences between Tunisian accounting system tax rules and the international standard as well as the tax regulations and tax liability are rated by TCPAs having 10 to 20 years of experience as the most important obstacles.

For tax obstacles, we note that the differences between Tunisian accounting system tax rules and the international standard as well as the tax regulations and tax liability are rated by TCPAs having 10 to 20 years of experience as the most important obstacles.

For economic obstacles, we observe that "costs of training and education" and "expenses related to the reorganization and the modification of the information system" are rated by TCPAs having networks of international customers as the most important obstacles. Costs related to "implementation of IFRS" and "cost of adoption and implementation" are considered by TCPAs having 10 to 20 years of experience as the most important obstacles. 
Finally, we found that:

- The TCPAs having a network of national and international clients consider poor monitoring of the implementation of an information system as the most important obstacle.

- The lack of dynamic and efficient markets is cited by TCPAs having 10 to 20 years of experience as the most important obstacle.

- The conservative attitude of managers and leaders is considered by non-teaching TCPAs as the most important obstacle.

Table 18. HCA according to the nature of the obstacles and the TCPAs

\begin{tabular}{|c|c|c|c|c|c|}
\hline & & $\begin{array}{c}\text { Obstacles of } \\
\text { accounting nature }\end{array}$ & $\begin{array}{c}\text { Obstacles of tax } \\
\text { nature }\end{array}$ & $\begin{array}{c}\text { Obstacles of } \\
\text { economic nature }\end{array}$ & Other obstacles \\
\hline \multirow[b]{3}{*}{$\begin{array}{l}\text { Customer } \\
\text { type }\end{array}$} & International & - Deferred tax (4.00) & & $\begin{array}{l}\text { Training and } \\
\text { education expenses } \\
\text { (4.86) } \\
\text { - Expenses related to } \\
\text { the reorganization } \\
\text { and the } \\
\text { modification of } \\
\text { information system } \\
\text { (4.71) }\end{array}$ & \\
\hline & National & & & & \\
\hline & $\begin{array}{l}\text { National and } \\
\text { international }\end{array}$ & $\begin{array}{l}\text { - The pro-cyclical } \\
\text { nature of the fair } \\
\text { value (4.25) } \\
\text { - The incompatibility } \\
\text { of practices with } \\
\text { IAS/IFRS } \\
\text { principles (3.88) } \\
\text { - Treatment of } \\
\text { financial } \\
\text { instruments (4.50) } \\
\text { - Treatment of } \\
\text { secondary } \\
\text { instruments: drifts } \\
\text { and hedging } \\
\text { instruments (4.25) } \\
\text { - The application of } \\
\text { IAS } 36 \text { (4.15) }\end{array}$ & & & $\begin{array}{l}\text { *The bad follow up } \\
\text { of the } \\
\text { implementation of an } \\
\text { information system } \\
(4.50)\end{array}$ \\
\hline \multirow{4}{*}{$\begin{array}{l}\text { Number of } \\
\text { years of } \\
\text { experience }\end{array}$} & Less than 10 years & & & & \\
\hline & $\begin{array}{l}\text { Between } 10 \text { and } 20 \\
\text { years }\end{array}$ & $\begin{array}{l}\text { - The complexity of } \\
\text { certain accounting } \\
\text { rules and } \\
\text { treatments (4.05) } \\
\text { - The pro-cyclical } \\
\text { nature of the fair } \\
\text { value (4.25) } \\
\text { - Actuarial method in } \\
\text { IAS } 19(4.30) \\
\text { - IFRS4 (4.20) } \\
\text { - Determination of } \\
\text { fair value (4.40) }\end{array}$ & $\begin{array}{l}\text { - Tax regulations and } \\
\text { tax liability }(4.35) \\
\text { - The differences } \\
\text { between tax rules } \\
\text { of the Tunisian } \\
\text { accounting system } \\
\text { and the } \\
\text { international } \\
\text { standards (1.56) }\end{array}$ & $\begin{array}{l}\text { - Costs related to the } \\
\text { application of IFRS } \\
\text { standards (4.63) } \\
\text { - Adoption and } \\
\text { implementation } \\
\text { costs (4.13) }\end{array}$ & $\begin{array}{l}\text { The absence of } \\
\text { efficient and } \\
\text { dynamic markets } \\
(4.40)\end{array}$ \\
\hline & $\begin{array}{l}\text { Between } 20 \text { and } 30 \\
\text { years }\end{array}$ & & & & \\
\hline & More than 30 years & & & & \\
\hline & Teaching TCPAs & & & & \\
\hline $\begin{array}{l}\text { Current } \\
\text { Position }\end{array}$ & Non-teaching TCPAs & & & & $\begin{array}{l}\text { The conservative } \\
\text { attitude of } \\
\text { managers and } \\
\text { leaders }(4.31)\end{array}$ \\
\hline
\end{tabular}




\section{CONCLUSION}

The adoption of IAS/IFRS in Tunisia presents some obstacles related to the nature of the Tunisian economy which is characterized by a strong presence of small and medium companies, to the differences between the tax system and the accounting system, the conservative attitude of leaders and the high concentration of ownership.

At the international level, the incompatibility of practices with the method of valorisation in fair value and the complexity of this new framework are the main obstacles to the adoption of IAS/IFRS. In recent years, several researches conducted by Bessieux et al. (2012); Zeghal \& Mhedhbi (2006); Abdelsalam \& Weetman (2003); and Choi \& Meek (2008) have attempted to identify factors allowing a better adoption of international accounting standards. The lack of research addressing the obstacles to the adoption of IAS/IFRS led us to identify and analyze the obstacles to the adoption of IAS/IFRS in the Tunisian context. We used a set of obstacles to the adoption and implementation of these standards found in the literature, particularly tax, accounting, economic, cultural and institutional obstacles.

For this research, we prepared a questionnaire that was sent to 400 Tunisians Certified Public Accountants (TCPAs). We were able to collect the responses from 71 TCPAs. To analyze the results of the survey, we conducted a Descriptive Analysis, a Principal Component Analysis and a Hierarchical Cluster Analysis of the different obstacles. The results of the analysis showed that the conservative attitude of managers and the lack of dynamic and efficient markets are the most important obstacles to adoption of IAS/IFRS in Tunisia according to the Tunisians Certified Public Accountants TCPAs). We detailed our analysis for the accounting, tax and economic obstacles. For the accounting, we found that the application of IAS 19, IAS 36 and IFRS 4 are the standards that cause more problems at the moment of their implementation according to the TCPAs. In addition, the deferred tax, the actuarial method and the treatment financial instruments are the most complex treatments in IAS/IFRS. Finally, the differences between the Tunisian accounting system and the international accounting system are undoubtedly an important obstacle. Concerning the tax obstacles, we found that companies prepare their financial statements first in accordance with tax rules. In fact, the differences between the tax rules of the Tunisian accounting system and the IAS/IFRS are undoubtedly an obstacle to a better adoption of them. In addition, another obstacle is the readiness of tax administration for the adoption of the IAS/IFRS. Finally, for the economic obstacles, we found that the IAS/IFRS' adoption and implementation costs and the costs related to their enforcement are the main economic obstacles.

However, like any study, our research is not without limitations. Indeed, the first limitation is with relation to the sample size. Second, the obstacles to the adoption of international accounting standards IAS/IFRS in Tunisia are probably not the same for every business sector. In fact, a cross-sector study of Tunisian companies can be conducted. Finally, specific study targeted at the Small and Medium-Sized Enterprises (SMEs) can be conducted to study the obstacles of the adoption of IAS/IFRS for SMEs in Tunisia.

\section{AUTHOR BIOGRAPHIES}

S. L. Boumediene has a Ph.D. in Business Administration (Accounting) from the University of El Manar, Tunisia. Before joining Montana State University-Billings, Dr. Boumediene taught both financial and managerial accounting at both the undergraduate and graduate levels at the top business schools in Tunisia. Dr. Boumediene has been publishing his research work in academic journals, such as the Journal of Applied Business Research and the International Journal of Business and Finance Research, among others. Dr. Boumediene published a book on statistical characteristics and quality of accounting information in 2013.

E-mail: salem.boumediene@msubillings.edu (Corresponding author)

R. Zarrouk has a Ph.D. in business administration (Accounting) from the University of Tunis, Tunisia. Dr. Zarrouk is an assistant professor in the department of Accounting and finance at ISCAE, La Manouba, Tunisia where he teaches International Financial Reporting Standards (IFRS) at both the undergraduate and graduate levels. Dr. Zarrouk published a book on IFRS in 2013. E-mail: universelleaudit@planet.tn. 
I. Tanazefti has a Master degree in accounting from the "High Institute of Accounting and Business Administration" (ISCAE), La Manouba. She received her Bachelor degree from the ISCAE with honors. Prior to joining "ABS EXPORT", an international accounting firm in Tunisia, she has been a research assistant at the ISCAE. E-mail: tanazefti-ines@live.com

\section{REFERENCES}

Abdelsalam, O. \& Weetman, P. (2003). "Introducing international accounting standards to an emerging capital market: Relative familiarity and language effect in Egypt”. Journal of International Accounting, Auditing and Taxation, vol.12, pp.63-84.

Bearden, W. O. \& Netemeyer, R. G. (1999). "Handbook of marketing scales: Multi-item measures for marketing and consumer behavior research" 2nd editon. Newbury Park, CA7 Sage.

Bhattacharjee, S. \& Islam, M. Z. (2009). "Problems of Adoption and Application of International Financial Reporting Standards (IFRS) in Bangladesh". International Journal of Business and Management, Vol.4, No.12, pp.165-175.

Carricano, M. Poujol, F. \& Bertrandias, L. (2010). "Analyse de données avec SPSS”. 2ième édition, Paris, Pearson Education France.

Choi, F. \& Meek, G. (2008). "International Accounting”. 6th 2dition. Pearson Prentice Hall

Churchill, G. A. Jr. (1995). "Marketing Research: Methodological Foundations". The Drydeu Press, G. Edition, New York, USA.

Desai, M. A. \& Dharmapala, D. (2006). "Corporate Tax Avoidance and High Powered Incentives”. Journal of Financial Economics 79 (1): 145-179.

Disle, C. \& Noël, C. (2007). "La révolution des normes IFRS: une convergence de la comptabilité vers la finance?". La Revue des Sciences de Gestion : Direction et Gestion, vol.42 (224:225), pp.17-27.

Evraert, S. \& des Robert, J. F. (2007). "French Accounting Revolution: implementing IFRS in French companies", in Godfrey J.M., \& Chambers K., Globalisation of Accounting Standards, Edward Elgar, Cheltenham.

Gélard, G. (2006). "Démarche normative et cadre conceptual”. Revue Française de Comptabilité, vol.393, pp. 35-39.

Hail, L., Leuz, C. \& Wysocki, P. (2010). "Global Accounting Convergence and the Potential Adoption of IFRS by the U.S. (Part II): Political Factors and Future Scenarios for U.S. Accounting Standards". Accounting Horizons, 24(4), 567 - 588.

Haller, A. (2002). "Financial accounting developments in the European Union: Past, events and future prospects". The European Accounting Review, Vol. 11, $\mathrm{n}^{\circ}$ 1, pp. 153-19.

Jermakowicz, E. K. (2004). "Effect of adoption of International Reporting Standards in Belgium: The evidence from BEL-20 companies". Accounting in Europe, pp.121-131.

Jermakowicz, E. K., Parther-Kinsey, J. \& Wulf, I. (2007). "The value relevance of accounting income reported by DAX-30 German companies". Journal of international Financial Management \& Accounting, 18(3), pp. 151-191.

Jopson, B. (2005). "Opposition mounts to IFRS 3 draft Accounting Standards", Financial Times, pp. 28.

Manzon, G. \& Plesko, G. (2002). "The relation between financial and tax reporting measures of income”, Tax Law Review 55, pp. 175-214.

Mir, M. Z. \& Rahaman, A. S. (2005). "The adoption of international accounting standards in Bangladesh-An exploration of rationale and process". Accounting, Auditing \& Accountability Journal, Vol. 18, pp. 816-841.

Shaviro, D. (2009). "The optimal relationship between taxable income and financial accounting income: analysis and a proposal". The Georgetown Law Journal, 97, pp. 423-484.

Street, D. \& Larson, R.K. (2004). “Large accounting firms' survey reveals convergence of two standard system in the European Union”. Advances in International Accounting, ${ }^{\circ} 17$, pp. 1-29.

Sucher, P. \& Jindrichovska, I. (2004). "Implementing IFRS: A case study of the Czech Republic". Accounting in Europe, 1, pp.109-141.

Vellam, I. (2004). "Implementation of International Accounting Standards in Poland: Can true convergence be achieved in practice?". Accounting in Europe, 1, pp.143-167.

Yaïch, A. (2006). « La nouvelle loi sur le renforcement de la sécurité financière », La revue comptable et financière, 73, pp. 3844

Zeghal, D. \& Mhedhbi, K. (2006). "An analysis of the factors affecting the adoption of international accounting standards by developing countries". The International Journal of Accounting, vol 41, pp.373-386. 